\title{
Research of Anti-reflective and Protective Symmetrical DLC Films Deposited by Pulsed Laser
}

\author{
Shuyun Wang ", Xu Liu, Weibing Bai \\ Wuhan Mechanical Technology College, Wuhan Hu Bei, 430075, China \\ paper1511@sina.com
}

Keywords: Diamond like carbon film; Pulsed laser deposition; Anti-reflective; Symmetric film on large area

Abstract. Femtosecond pulsed laser(800nm, 120fs, 1000Hz) was used. And methods of element doping, abaxially rolling and moving were applied. Problems of conflict between transmission and inner-stress, and large area asymmetric of diamond like carbon (DLC) films deposited by pulsed laser were overcome. Hydrogen-free DLC film was deposited on silicon substrates. The transmission at $3-5 \mu \mathrm{m}$ of the silicon sample coated by DLC film on one side was larger than $68 \%$. The nano-hardness was up to 40-50GPa. Asymmetry of DLC film in size of $\varphi 125 \mathrm{~mm}$ was smaller than $2 \%$. Furthermore there was no nicks on the film after rubbed 105 times by $9.8 \mathrm{~N}$ rubber.

\section{Introduction}

Silicon and germanium are the main optical materials at $3-5 \mu \mathrm{m}$ or $8-12 \mu \mathrm{m}^{[1,2]}$. But the transmission, hardness and stability of these materials are not high enough, and they are easy to be nicked and mildewed. As DLC films have many merits similar to diamond, such as high hardness, anti-reflective at wide spectrum and high stability. One effective approach is to plate common infrared anti-reflective film on the inside surface and plate DLC films on the outside surface. This method will not only improve the infrared transmission, but also advance performances such as mechanical and chemical stability.

Chemical vapor deposition(CVD) has developed as a ripe method to deposit DLC films. But it need high temperature and the film contain hydrogen. The performances such as hardness, thermal and chemical stability are not excellent enough. As one new technic, pulsed laser deposition(PLD) can deposit hydrogen-free DLC films under room temperature with high speed ${ }^{[3,4]}$. Even so, there are still some problems in PLD method. DLC films with high $\mathrm{sp}^{3}$ bonds content show high transmission but at the same time their inner-stress are also high. Furthermore, the plasma sputtered by laser is similar to taper, it's difficult to deposit uniform film on large area.

In our research, femtosecond pulsed laser was used to deposit DLC films. Through a great lot of experiments, we validated the impact rules of DLC films by laser parameters, such as laser intensity ${ }^{[5-7]}$. Through means of element doping, abaxially rolling and moving, we deposited excellent DLC films on silicon substrates and resolved the problems of DLC films by PLD.

\section{The effect of element doping to DLC film}

To reduce the inner-stress of DLC film, researchers tried to mix some elements to DLC film, such as $\mathrm{Si} 、 \mathrm{Ti} 、 \mathrm{~W} 、 \mathrm{~B} 、 \mathrm{P}^{[8-10]}$. Many elements have big extinctive coefficient, if doped into DLC film, the transmission of DLC film will be reduced. Compared to other elements, Si has some merits. Si fits well with silicon substrate and impossibly to form $\pi$ bonds which indwell in $\mathrm{sp}^{2}$. It's helpful to increase $\mathrm{sp}^{3}$ bonds content to dope Si into DLC films whose $\mathrm{sp}^{3}$ bonds content are not too high. And this will also improve the transmission. Besides, as the energy of $\mathrm{Si}-\mathrm{C}$ bond $(3.21 \mathrm{eV})$ is smaller than that of C-C bond $(3.70 \mathrm{eV})$, aberrance of $\mathrm{C}$ bonds can be slacked which will make the inner-stress decline greatly.

Only few people have studied doped silicon DLC film. Earliest overseas report about doped silicon DLC film was in $1998^{[9]}$, and while domestic until recent years ${ }^{[10]}$. Anyway, the actions of doping silicon have been found. It's useful to decrease inner-stress and improve adhesion. 


\section{Experiments research}

\section{Experiment equipment}

Ti:Sapphire femtosecond laser $(800 \mathrm{~nm}, 120 \mathrm{fs}, 1000 \mathrm{~Hz})$ was used. The vacuum limit of deposition chamber is $6 \times 10^{-5} \mathrm{~Pa}$. The schematic deposition system is shown in figure 1 . Laser beam is focused onto graphite target by a $50 \mathrm{~cm}$ focal length lens with an incidence angle of $55^{\circ}$. The 99.999\%-purity graphite target and the n-type single crystal silicon(100) substrates are placed parallel into the chamber. And their distance can be changed from $40 \mathrm{~mm}$ and $80 \mathrm{~mm}$. Both the target and substrate holders can rotate round their main axis during the irradiation to make the films uniform. Furthermore, the substrate holder can move up and down. Ambient atmosphere channels and ion sputtering devices are equipped to the chamber. The graphite was ultrasonically cleaned in distilled water and alcohol for 5 minutes respectively. The silicon slices were firstly dipped in 5\% HF for 10 minutes, then cleaned in alcohol with ultrasonic wave for 5 minutes. Both graphite and substrates should be put into the chamber immediately after drying. To improve the adhesion of film we use $\mathrm{Ar}^{+}$ plasma to sputter sample surface for 10 minutes before deposition.

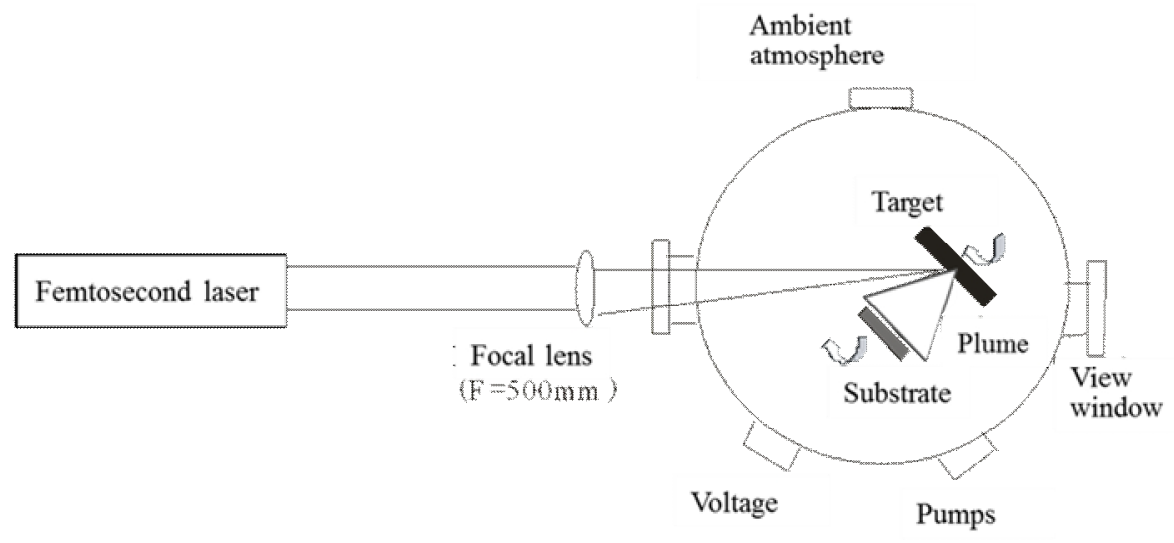

Fig.1 Schematic PLD system

\section{Experiment process and results}

In our experiments, we firstly deposited DLC films in vacuum and to find best distance between target and substrate. Under single pulse energy of $1.1 \mathrm{~mJ}\left(8.7 \times 10^{13} \mathrm{~W} / \mathrm{cm}^{2}\right)$, we deposited films on silicon substrates at $4 \mathrm{~cm}$ and $5 \mathrm{~cm}$ distance for $4 \mathrm{~min}$ respectively. Through these experiments, we found the transmission at $5 \mathrm{~cm}$ was better than $4 \mathrm{~cm}^{[5]}$.

\section{Deposit Si doped DLC films}

We sticked Si slice onto graphite target surface to dope Si to the film, as shown in figure 2. When target holder rotated, laser ablated graphite and Si by turns and deposited Si doped DLC film. Through changing the width of silicon slice, DLC films with different Si quantity doped can be deposited.

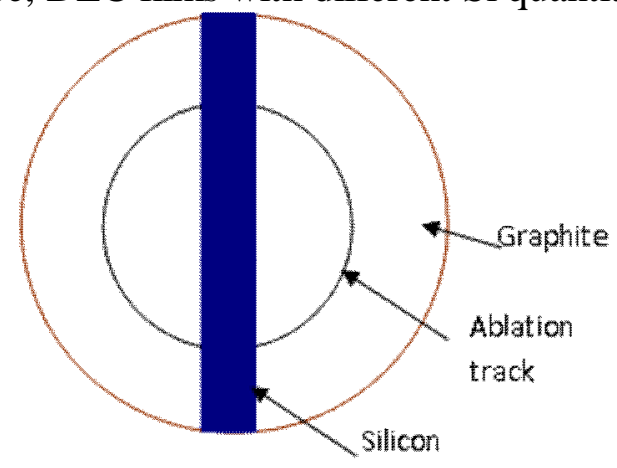

Fig. 2 Laser ablation track while doping Si to DLC film 
We deposited films with different Si quantity doped. Si quantity doped in sample SiI、SiJ、SiK was $4 \%, 7 \%, 11 \%$ respectively. We tested performances of these samples and discovered that all transmissions of these three samples were higher than those pure DLC films. Furthermore, the quantity of Si doped was not the higher, the better. The transmission of sample SiJ was highest. Transmission peak at $3 \sim 5 \mu \mathrm{m}$ reached $68.2 \%$. Ellipsometer was applied to test the optical characteristics of the films. Refraction index of film doped silicon was lower than that of non-doped. This also explained the reason of transmission improved after doped silicon. To sample SiJ, the refractive index of DLC film was 2.17. The academic transmission simulated by film design software was $68.7 \%$. The actual transmission $68.2 \%$ was only smaller $0.5 \%$ than $68.7 \%$, as shown in figure 3 . Furthermore, we plated common $3 \sim 5 \mu \mathrm{m}$ anti-reflection film on other side of sample SiJ. The transmission peak at 3 5 $\mu \mathrm{m}$ was $93 \%$ and average $\geq 91.7 \%$. Nano Indenter was used to test film nano-hardness and the hardness up to 40-50GPa. Furthermore, after rubbed by $9.8 \mathrm{~N}$ rubber for $10^{5}$ times, there was no nicks on the film. This proved that the adhesion performance of DLC film could meet the demand of common optical application.

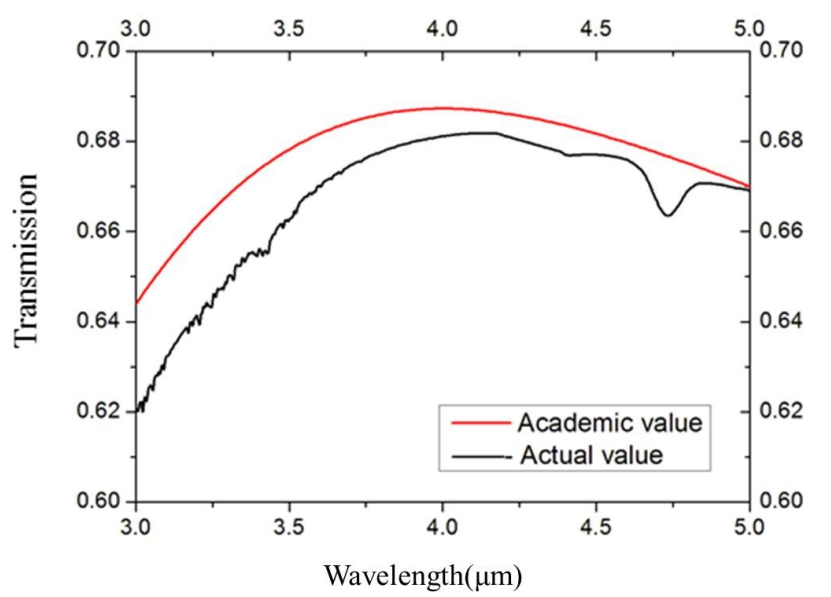

Fig. 3 Academic and actual transmission compare of Si doped DLC film

\section{Symmetrical DLC film on large area}

The shape of plasma generated in PLD was similar to taper. The distribution of kinetic energy and numbers of particles was very asymmetric, so the performances and thickness of films deposited by PLD was also asymmetric. The thickness of film by PLD was usually thick on center and thin on edge. This restrict the application of PLD. We adopted abaxially rolling and moving method to improve uniformity. As shown in figure 4, the initial center of substrate was apart from the center of plasma, and the substrate holder moved along its radial direction with variational velocity. The substrate holder moved quickly when it moved close to the center of plasma. When the substrate holder moved far from the center of plasma, it moved slowly. Furthermore, the substrate rotated round its own axis. Through this method, the film thickness on the center would not be too thick, and the film thickness on the edge would not be too thin. Symmetrical DLC film on large area would be deposited by optimizing the distance between substrate, the range of substrate holder moved, time of substrate holder stopped at different position. In our experiments, we found that the optimal conditions were as follows: the initial distance between substrate center and plasma center was $22 \mathrm{~mm}$, the substrate holder moved under velocity from $0.5 \mathrm{~mm} / \mathrm{s}$ to $2 \mathrm{~mm} / \mathrm{s}$. The biggest distance between substrate center and plasma center was $75 \mathrm{~mm}$, and the substrate holder stayed $4 \mathrm{~s}$ at this position, then the substrate holder moved to its initial position under velocity from $0.5 \mathrm{~mm} / \mathrm{s}$ to $2 \mathrm{~mm} / \mathrm{s}$. After this process repeated for many times, symmetrical DLC film on $\varphi 125 \mathrm{~mm}$ silicon substrate was deposited. The film thickness was tested by ellipsometer, and the film thickness changed between $404.9 \mathrm{~nm}$ and $412.9 \mathrm{~nm}$, average thickness was $407.8 \mathrm{~nm}$. The thickness asymmetry of film was smaller than $2 \%$, and the transmission of different position all larger than $68 \%$. 


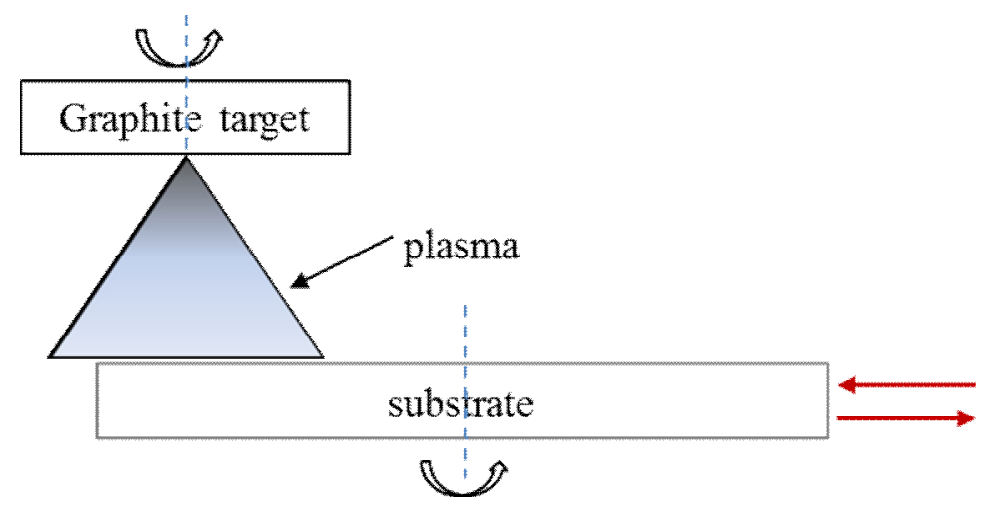

Fig. 4 Abaxially rolling and moving method

\section{Conclusions}

New technic of femtosecond pulsed laser deposition was used to prepare DLC films. Method of doping Si element was used to improve the performances of DLC film. Experiments proved that doping suitable Si element was useful to improve the integrated performances of DLC film, including

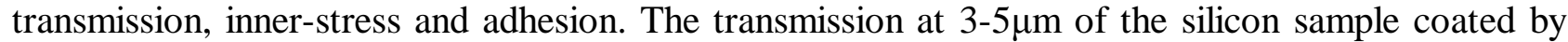
DLC film on one side was larger than 68\%. The nano-hardness was up to 40-50GPa. Through method of abaxially rolling and moving, symmetrical DLC film on large area was gained. Asymmetry of DLC film in size of $\varphi 125 \mathrm{~mm}$ was smaller than $2 \%$.

\section{References}

[1] O M Kutsay, B A Gorshtein, Diamond and Related Materials, 10 (2001) 1846-1848.

[2] N V Novikov, A G Gontar, Diamond and Related Materials, 9 (2000) 792-795.

[3] D. B. Chrisey, G. K. Hubler. Pulsed laser deposition of thin film, New York, 1994, 13-19,199-227.

[4] A. A. Voevodin, M. S. Donley, Surface Coating Technology, 82(1996)199.

[5]S. Y. Wang, Y. L. Guo, X. B. Wang, 4th International Symposium on Advanced Optical Manufacturing and Testing Technologies, 2782(2008)7282OR.

[6]S. Y. Wang, Y. L. Guo, X. Liu, High Power Laser and Particles beams, 8(2010)1705-1709.

[7]Y. Cheng, S. Y. Wang, Y. L. Guo, Optics \&Optoelectronic technology, 3(2011)51-57.

[8]B. Kleinsorge, A. Ilie, M Chhowalla, Diamond and Related Materials, 7(1998)472-476.

[9]S. S. Camargo Jr, R. A. Santos, A. L. Baia Neto, Thin Solid Films, 332(1998)130-135.

[10]D. C. Zhao, N. Ren, Z. J. Ma, Acta Physica Sinica, 3(2008)1935-1940. 